\title{
Built environment correlates of walking for transportation: Differences between commuting and non-commuting trips
}

\section{Jixiang Liu}

The University of Hong Kong

u3004679@connect.hku.hk

Longzhu Xiao (corresponding author)

City University of Hong Kong

longzxiao2-c@my.cityu.edu.hk

\author{
Jiangping Zhou \\ The University of Hong Kong \\ zhoujp@hku.hk
}

\begin{abstract}
As a sustainable mode of travel, walking for transportation has multiple environmental, social, and health-related benefits. In existing studies, however, such walking has rarely been differentiated between commuting and non-commuting trips. Using multilevel zeroinflated negative binomial regression and multilevel Tobit regression models, this study empirically examines the frequency and duration of commuting and non-commuting walking and their correlates in Xiamen, China. It finds that (1) non-commuting walking, on average, has a higher frequency and longer duration than commuting walking; (2) most socio-demographic variables are significant predictors, and age, occupation, and family size have opposite-direction effects on commuting and non-commuting walking; and (3) different sets of built environment variables are correlated with commuting and noncommuting walking, and the built environment collectively influences the latter more significantly than the former. The findings provide useful references for customized interventions concerning promoting commuting and non-commuting walking.
\end{abstract}

Keywords: Walking, walking for transportation, built environment, commuting and non-commuting trips, China

\section{Article history:}

Received: Novermber 29, 2020

Received in revised form: June

4, 2021

Accepted: August 5, 2021

Available online: October 20, 2021

\section{Introduction}

Walking is an integral part of physical activity, which is easy to undertake with no special training or equipment required, and it is associated with a reduction in risk of premature death and non-communicable diseases (NCDs), such as obesity, type 2 diabetes, chronic heart disease, hypertension, cardiovascular diseases, and depression (Hanson \& Jones, 2015; Lee \& Buchner, 2008; Pucher et al., 2010; Tschentscher et al., 2013). At the same time, walking can also be a type of primal, convenient, cheap, and sustainable mode of transport, and has been widely recognized to be beneficial to mitigation of transport congestion, reduction of environmental pollutants, and improvement of social interaction (Ghani et al., 2016; Litman, 2010; Maizlish et al., 2017; Wood et al., 2010). Walking is a multipurpose behavior. Walking for transportation is defined as walking with a utilitarian destination, i.e., "walking

Copyright 2021 Jixiang Liu, Jiangping Zhou \& Longzhu Xiao

http://dx.doi.org/10.5198/jtlu.2021.1933

ISSN: $1938-7849$ | Licensed under the Creative Commons Attribution - Noncommercial License 4.0

The Journal of Transport and Land Use is the official journal of the World Society for Transport and Land Use (WSTLUR) and is published and sponsored by the University of Minnesota Center for Transportation Studies. 
to/from work, to do errands, or to go from place to place (Ghani et al., 2016)"; by contrast, walking for recreation/leisure is defined as walking without a destination, i.e., walking just for fun, exercise or walking the dog. In the modern era characterized by extensive urban expansion, ever-increasing motorization, and ever-escalating pace of life, the transportation nature of walking has been increasingly shrinking. In the U.S., the 2010 Census revealed that there were only $2.77 \%$ of the employed in the urban areas commute on foot (Fan et al., 2017), and the 2010 National Health Interview found that only $29.4 \%$ of the respondents ever walked for all kinds of transportation purposes (including commuting) in the past week (Paul et al., 2015). In the developing world, on the one hand, walking is still an important travel mode, taking up a high share of transportation. A recent study found that in Beijing and Xi'an, China, $15 \%$ and $18 \%$ of the commuting trips are completed by walking, respectively (Yang et al., 2019). On the other hand, faced with rapid urbanization, motorization, and economic and social transition, developing countries like China are experiencing a rapid decline in walking, especially walking for transportation (Day, 2016; $\mathrm{Ng}$ et al., 2009). Walking for transportation is desirable as integrating walking into the everyday routines and/or necessary activities can effectively promote total frequency and duration of physical activity, thus obtaining significant environment- and health-related benefits. Hence, to stop and even reverse the declining trend of walking for transportation, especially in the developing context, it is critical to look closely into the underlying mechanism through which walking for transportation is affected by the built environment.

Much has been done on walking for transportation in recent years, concerning its definition, characteristics, and influencing factors, as well as its differences with walking for recreation (Kamruzzaman et al., 2016; Kang et al., 2017; Paul et al., 2015). However, most of the existing studies' regional focuses are developed countries and regions, despite it is in the developing world that there has been a dramatic declining trend of walking for transportation. If there were no timely intervention, the trend is likely to be irreversible. To provide useful references for the intervention, more studies should focus on the developing world. Moreover, walking for transportation is complex and can be further categorized by diverse purposes, for example, commuting and non-commuting. Commuting and non-commuting walking can be significantly different, due to their different spatial and temporal constraints. However, seldom has walking for transportation been differentiated between commuting and non-commuting and examined from the comparative perspective. The existing studies on walking for transportation addressed commuting and non-commuting purposes separately, and few studies dealt with them simultaneously.

Against the above backdrop, this study, taking Xiamen, China, as the case and employing diverse statistical methods, comparatively looks into the built environment correlates (represented by 5Ds model) of the frequency and duration of transportation walking for commuting and non-commuting purposes. It contributes to the current research and practices in the following aspects. First, it sheds light on the characteristics and influencing factors of commuting and non-commuting walking and their differences, thus enlightening policy-makers and practitioners with the differences between specific domains of walking and helping avoid "one-size-fits-all" type of policies. Second, there are hundreds of middle-sized cities in China and beyond. Yet, they are understudied. They are different from the star cities and cannot be fully represented by them (e.g., Beijing and Shanghai, which draw the most academic attention). Xiamen is a typical middle-sized city, and moreover, it is among the most walkable cities in China. Hence, an empirical case study of Xiamen can produce relevant references for other middle-sized cities.

The remainder of this paper is organized as follows. The relevant literature is reviewed in Section 2. The data and methods are introduced in Section 3. The research results are described and explained in Section 4, and further discussed in Section 5. Section 6 concludes with the contributions and limitations of this study. 


\section{$2 \quad$ Literature review}

\subsection{Walking for multiple purposes}

Despite the multipurpose nature of walking, and that walking for such different purposes may be triggered and affected by even the same factor(s) in distinct ways, walking has been treated as a homogeneous behavior by a great number of prior studies (e.g., Handy et al, 2006; Herrmann-Lunecke et al., 2021; Larrañaga et al., 2016; Saelens \& Handy, 2008). Without distinguishing different domains of walking and their influencing factors, the generalizability and applicability of findings of such studies will be weakened, and "one-size-fits-all" type of interventions and policies for promoting walking can prevail. In a comprehensive review, Giles-Corti et al. (2005) pointed out the significance of distinguishing different domains of walking behavior and called on increased specificity in environment-walking behavior research. Subsequently, increased efforts have been made to elaborate on the differences between walking for transportation and recreation. For example, Ghani et al. (2016) found that in Brisbane, Australian women and older persons were more likely to have recreational walking, and that such gender and age differences varied among different communities. Paul et al. (2015) confirmed that walking for transportation was shorter and more prevalent than that for recreation (leisure). Whereas, on the contrary, in a recent study, Kang et al. (2017) found that transportation (utilitarian) walking was much more prevalent than recreation walking in their sample (nearly 5,000 walking trips); on the other hand, they also found that transportation walking is much shorter than recreation walking, echoing the aforementioned two studies, and that the former is faster than the latter in speed.

Still, walking for transportation needs to be further broken down because it is made up of more than one purpose, for example, commuting and non-commuting. Commuting walking incorporates walking to/from workplace and school, while non-commuting walking encompasses walking to and from destinations other than workplace and school. Commuting and non-commuting walking can be significantly different because commuting travel may be much more spatially and temporally stable, whereas non-commuting travel can be far more flexible (Ding et al., 2017). In the developed context, the proportion of walking as a commuting mode is extremely low, especially in North America and Australia; for example, in the U.S., by 2012, only $2.8 \%$ of people walk to work (McKenzie, 2017). As a result, little research in the developed context has focused on commuting walking separately and specifically, despite the notable exception of the study by Celis-Morales et al. (2017), which, as a long-term prospective cohort study, found that commuting walking was associated with lower risk of CVD in the U.K. By contrast, in the developing context, studies delving into commuting walking specifically are increasing (e.g., Hatamzadeh et al., 2020; Neves et al., 2021). However, very few studies examined and/ or compared commuting and non-commuting walking simultaneously.

On the one hand, as discussed, walking for different purposes are substantially different in terms of trip characteristics and influencing factors; on the other hand, they can be under the constraints of a holistic budget. The proposition of "physical activity budget" (Forsyth et al., 2008; Forsyth et al., 2009) suggests that people who do more physical activity for a certain purpose do less for other purposes, which may be due to the constraints of energy, time, enthusiasm, etc. Hence, it is reasonable to infer that people who walk more for transportation may walk less for recreation, and factors potentially promoting the former may reduce the latter. To take it one step further, it is also reasonable to hypothesize that a "walking for transportation budget" exists, which constrains commuting and non-commuting walking.

\subsection{Built environment correlates of multipurpose walking}

Among the potential influencing factors of walking in general and walking for certain specific purposes in particular, the built environment has drawn extensive research and practical attention because the 
built environment is comparatively easily modifiable and cost-effective, and hence can potentially benefit a larger group of people (Fan et al., 2017).

Treating walking as a homogeneous/intact behavior, numerous studies have analyzed the built environment and confirmed its significant impacts on walking (Herrmann-Lunecke et al., 2021; Huang et al., 2019; Larrañaga et al., 2016; Lin \& Moudon, 2010). Among the built environment features or elements, the 5Ds framework epitomizes how the built environment can be quantified and abstracted. Specifically, the 5Ds framework tries to delineate the built environment from 5 dimensions, including density, diversity (land-use mix), design (pedestrian-friendly design), destination accessibility, and distance to the transit (Ewing \& Cervero, 2001, 2010; Ewing et al., 2009). In general, higher density (population and employment) (Bentley et al., 2018), higher land-use mix (Wang et al., 2021), better design (often measured by intersection density) (Kang, 2017; Koohsari et al., 2017), higher destination accessibility (distance to CBD) (Chudyk et al., 2015; Ewing et al., 2015), and a shorter distance to transit (Kang, 2018; Wang \& Cao, 2017) are widely found to be associated with a higher frequency or longer duration of walking. However, inconsistencies and discrepancies exist, mainly due to the differences between developed and developing contexts (Boakye-Dankwa, Barnett et al., 2019; Boakye-Dankwa, Nathan, et al., 2019; Lu et al., 2018; Lu et al., 2017), which entails more studies in the understudied developing context.

Moreover, along with the increased attention towards walking for different purposes, increasingly more research has been focusing on impacts of the built environment on walking for transportation specifically and/or comparison between those on walking for transportation and recreation. For example, an international comparative study found transportation walking of respondents in 14 cities across 10 countries to be positively associated with population density, land-use mix, intersection density, and the number of parks (Christiansen et al., 2016). Wang et al. (2021) found that higher land-use mix can significantly increase walking for both transportation and recreation, whereas higher intersection density can increase transportation walking but decrease recreational walking. However, Lu et al. (2017) found in Hong Kong that land-use mix and street connectivity were insignificantly associated with walking for either transport or leisure, and that population density was only positively related to walking for transportation but had an inverse-U-Shape association with leisure walking.

Researchers, particularly those in the developing context, have started to separately examine the built environment correlates of commuting and non-commuting walking. Hatamzadeh et al. (2020), for instance, explored the effects of built environment factors on walking duration and the probability of walking for working in the City of Rasht, Iran, applying a structural equation modeling; they found that job-housing balance was the most significantly associated with propensity and duration of walking. Employing Sáo Paulo city, Brazil as the case, Neves et al. (2021) found that diversity (i.e., land-use mix) had the most significant effects on the propensity of walking to workplace and school. The effects of the built environment on non-commuting walking also draw some research attention. For example, Schneider (2015), in their study in San Francisco, found that the probability of walking to shopping districts was significantly associated with the accessibility of the district (walking distance). Cheng et al. (2020) applied the random forest method to examine the effects of the built environment on walking behavior of the elderly in Nanjing, China; they revealed the significant positive impacts of population density and land-use mix within certain ranges. However, very few studies have simultaneously examined the impacts of the built environment on commuting and non-commuting walking. The only two exceptions, to the best of our knowledge, are the comparative studies by Zhao and Wan (2020) and Chan et al. (2019). The former divided walking into commuting walking, living walking (equivalent to the non-commuting walking in our study), and recreational walking; on the basis of the case of Beijing, 
they found that higher density, land-use mix value, and better street design can promote walking, and that commuting walking was less affected by the built environment (Zhao \& Wan, 2020). The latter, by contrast, categorized walking into walking for work/school (equivalent to commuting walking in our study), walking for recreation, and walking for household responsibilities (similar to non-commuting walking in our study); on the basis of Shenzhen, China, they uncovered the considerable differences in the built environment effects on different types of walking (Chan et al., 2019).

\section{Data and methods}

\subsection{Study area}

Xiamen, located on the southeast coast of China, is a well-known tourism city and special economic zone. It is famous for its high walkability. In a recent report on the appraisal of walking friendliness of Chinese Cities finished by the Natural Resources Defense Council and School of Architecture of Tsinghua University in 2017, Xiamen ranked first among 36 major cities of China. In recent years, Xiamen has been devoting even more to enhancing its infrastructures beneficial for walking. For example, several city-level walking projects have been completed in succession, including the Xiamen Healthy Walking Path (longer than 20 km), Wuyuan Bay Walking System, Haicang Bay Active Travel System and Yundang Lake Walking System, making Xiamen more outstanding in walkability. Hence, Xiamen is a suitable case for studying walking behavior.

By 2016, Xiamen has an area of 1,699 km², of which $334 \mathrm{~km}^{2}$ is urbanized areas. Figure 1 illustrates Xiamen city and its administrative division as well as the major destinations and infrastructures. As shown, the administrative hierarchy of Xiamen has three levels, i.e., city, district, and community. Six districts, i.e., Siming District, Huli District, Haicang District, Jimei District, Tong'an District, and Xiang'an District constitute Xiamen's second administrative hierarchy, as represented in Figure 1 by 1 to 6 successively. Xiamen Island, which is fully occupied by Siming and Huli Districts, is the most developed and urbanized area of Xiamen, and is separated from the other four districts located in the continent by sea. 508 communities, which act as the spatial analysis units of this study, constitute the third administrative hierarchy of Xiamen. On average, each community has an area of $3.34 \mathrm{~km}^{2}$, close to or smaller than the size of the units of analysis (typically the traffic analysis zones [TAZ]) of many prior studies in the domain of travel behavior research (e.g., Cheng, Chen, et al., 2019; Ding et al., 2018). Hence, it is appropriate in this study to utilize the community as the geographic analysis unit. 


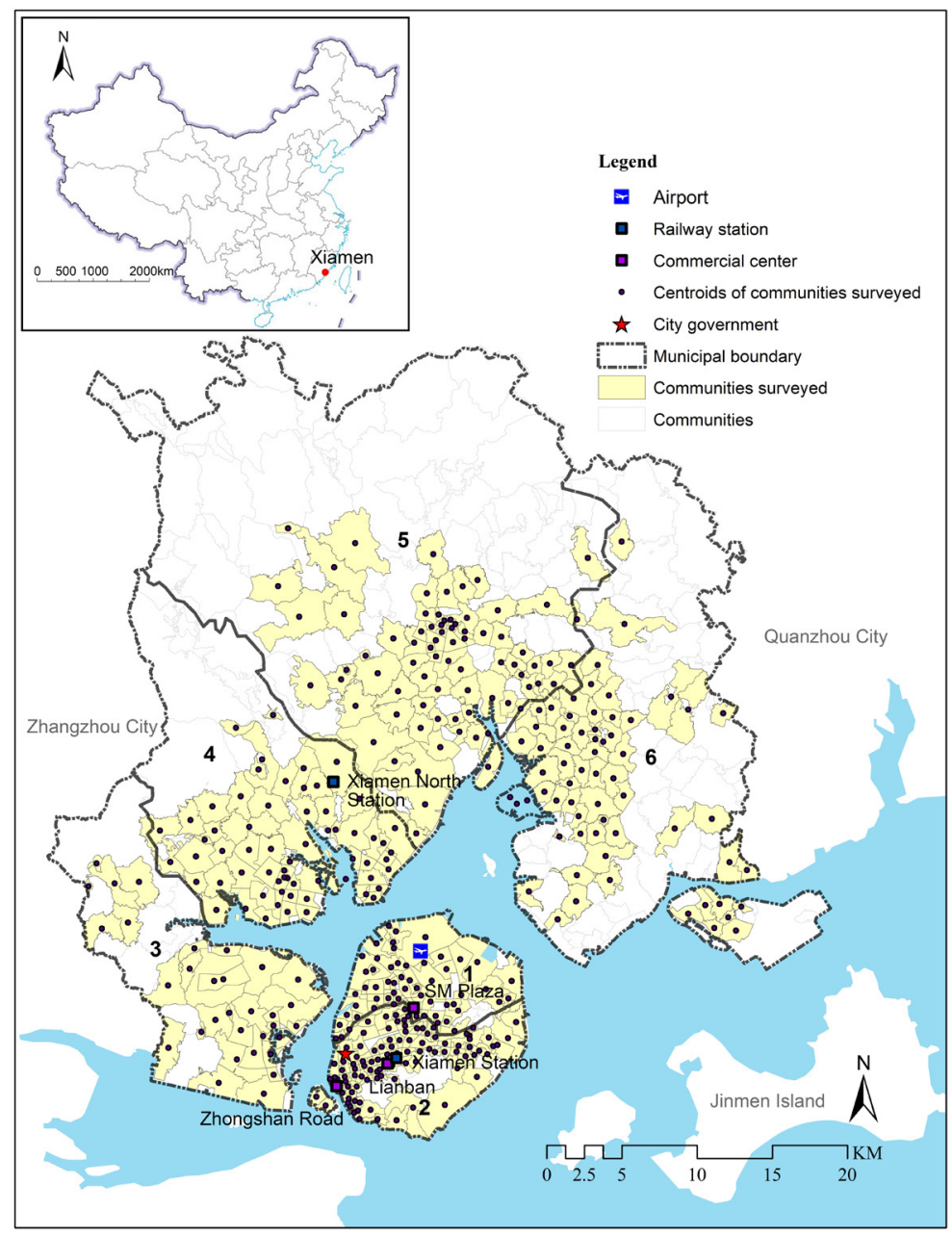

Figure 1. The study area: Xiamen City and the communities

\subsection{Data}

Three types of data were employed in this study, i.e., walking behavior data, socio-demographic data, and community built environment data. They are obtained from diverse sources.

Walking behavior data and individual and household level socio-demographic data were extracted from the Travel Survey of Xiamen Residents 2015 (TSXR 2015) dataset. Conducted every five years, TSXR is a comprehensive long-term travel behavior survey scheme, and TSXR 2015 is the latest round. The TSXR 2015 adopted the stratified sampling method. It covered 368 out of 508 communities (presented in light yellow green in Figure 1), and 120,603 residents participated in the survey (with a sampling rate of 3.05\%). Among the 96,010 questionnaire forms finished and recovered, 93,812 were valid (with a response rate of $97.7 \%$ ). Given the reasonable sampling strategy and high sampling and response rate, TSXR 2015 can represent the Xiamen residents well and can be used to effectively reveal their walking behaviors.

In the dataset, all the trips $(n=219,152)$ finished by all the 96,010 respondents during the whole 24 hours of the survey day were recorded. Among the respondents, 50,514 of them make at least one commuting trip, and they are extracted to analyze the walking for commuting; by contrast, 35,007 
respondents make at least one non-commuting trip, and they act as the subset for analyzing walking for non-commuting. The walking duration, starting time, origins and destinations, and walking purposes are also included in the dataset. Additionally, the dataset incorporates the socio-demographic characteristics of individuals (e.g., age, occupation and educational attainment) and families (e.g., residence type, availability of vehicle) as well.

The built environment data were obtained from Xiamen Institute of Urban Planning and Design, Gaode map, and Xiamen University, including but not limited to land use, transportation infrastructure, and urban design features of Xiamen city.

\subsection{Methods}

To probe into the characteristics and influencing factors of commuting and non-commuting walking, we first conducted Chi-square tests to compare the average frequency and duration of two kinds of walking. Then, two multilevel zero-inflated negative binomial regression models and two multilevel Tobit regression models were built and estimated. The details of them are further discussed as follows.

\subsubsection{Dependent variables}

We constructed two kinds of dependent variables for the statistical models, namely the frequency of commuting/non-commuting walking that indicates the total counts of a certain individual's walking for commuting/non-commuting purpose $(0,1,2, \ldots, \mathrm{n})$, and the duration of commuting/non-commuting walking that indicates the total duration of an individual's walking for commuting/non-commuting. Here, the key lies in the reclassification of walking purposes. In the original dataset, there are multiple kinds of utilitarian purposes, and we reclassified them into commuting and non-commuting. Specifcally, we categorize the walking trips to and from workplace or school into commuting walking while the other walking trips as non-commuting walking (mainly including walking trips for shopping, entertainment, etc.).

\subsubsection{Independent variables}

Two sets of independent variables were constructed and examined, including socio-demographic variables and built environment variables.

Individual socio-demographic variables incorporate age, gender, hukou (i.e., the household registration system in China) status (Xiamen hukou and non-Xiamen hukou), educational attainment (coded into middle school and below, high school to junior college and undergraduate and above), and occupation status, which is coded into blue-collars (those employed in basic positions such as commercial and service, agriculture, and forestry), students, white-collars (those in middle-to-high positions, such as professionals, business personnel and military personnel), and officials (governmental officials and executives). Household socio-economic variables include residence size, residence type (coded into self-owned, danwei (i.e., Chinese working unit-assigned, and self-rental residence), family size (coded into 1 to 2,3 to 7 , and 8 to 10), and motor vehicle availability.

Community built environment variables are mainly developed and calculated following the "5Ds" framework. "5Ds" incorporate density, diversity, design, destination accessibility, and distance to transit, which are widely confirmed to be significant determinants of walking, as discussed in the last section. Specifically, population density, land-use mix, and intersection density can indicate the development pattern of the built environment. Job density, bus stop density, and daily public facility density can indicate the local accessibility of the community, while the distance to the city center can measure the 
regional accessibility. In particular, daily public facility density incorporates some facilities with local characteristics, such as vegetable markets, breakfast stores, chess and cards room, and cultural palace. The descriptions and formulas are presented in Table 1.

Table 1. Descriptions and formulas of the community built environment variables

\begin{tabular}{|c|c|c|}
\hline Variable & Description & Formula \\
\hline \multirow[t]{2}{*}{ Population density } & \multirow[t]{2}{*}{ Count of residents per unit of area. } & Count of residents within a community \\
\hline & & Area of the community (ha) \\
\hline \multirow[t]{2}{*}{ Job density } & \multirow[t]{2}{*}{ Count of enterprises per unit of area. } & Count of enterprises within a community \\
\hline & & Area of the community (ha) \\
\hline \multirow[t]{4}{*}{ Land-use mix (entropy) } & \multirow{4}{*}{$\begin{array}{l}\text { We adopted the Entropy method, with } \\
\text { nine major types of POIs identified, } \\
\text { including recreation and entertain- } \\
\text { ment, residence, medical service, } \\
\text { governmental office, transportation, } \\
\text { education and research, commerce, } \\
\text { financial service, and catering. }\end{array}$} & $L U M=(-1)\left(\sum_{i=1}^{n} p_{i} \ln \left(p_{i}\right)\right)$ \\
\hline & & $\mathrm{n}=9$ \\
\hline & & $p_{i}=$ Count of ith kind of POI within a community \\
\hline & & Count of 9 kinds of POI within the community \\
\hline \multirow[t]{2}{*}{ Intersection density } & \multirow{2}{*}{$\begin{array}{l}\text { Count of 3-or-more-way intersections } \\
\text { per unit of area. }\end{array}$} & Count of intersections within a community \\
\hline & & Area of the community (ha) \\
\hline Distance to the city center & $\begin{array}{l}\text { Distance from the centroid of the com- } \\
\text { munity to the city center (i.e., the City } \\
\text { Government) }\end{array}$ & Formula: N/A; Unit: km. \\
\hline \multirow[t]{2}{*}{ Daily public facility density } & \multirow{2}{*}{$\begin{array}{l}\text { The analysis involves several types of } \\
\text { POIs of daily service, including shop- } \\
\text { ping, food and beverage, entertain- } \\
\text { ment, medical service, and financial } \\
\text { service. The density of such POIs are } \\
\text { calculated for each community. }\end{array}$} & Count of daily POIs within a community \\
\hline & & Area of the community (ha) \\
\hline \multirow[t]{2}{*}{ Bus stop density } & \multirow[t]{2}{*}{ Count of bus stops per unit of area. } & Count of bus stops within a community \\
\hline & & Area of the community (ha) \\
\hline
\end{tabular}

Table 2 presents the descriptive statistics of the aforementioned two sets of independent variables. 
Table 2. Descriptive statistics of independent variables

\begin{tabular}{|c|c|}
\hline Variables & Mean (SD)/Percentage \\
\hline Sample size of communities & $237.14(294.07)$ \\
\hline Age & $38.20(16.02)$ \\
\hline Residence size (unit: $\mathrm{m}^{2}$ ) & $100.58(63.74)$ \\
\hline Population density (unit: $\mathrm{n} / \mathrm{ha}$ ) & $161.67(152.86)$ \\
\hline Job density (unit: $\mathrm{n} / \mathrm{ha}$ ) & $3.67(5.86)$ \\
\hline Land-use mix (Entropy) & $0.65(0.17)$ \\
\hline Intersection density (unit: n/ha) & $0.19(0.21)$ \\
\hline Daily public facility density (unit: $\mathrm{n} / \mathrm{ha}$ ) & $2.45(4.61)$ \\
\hline Distance to the city center (unit: $\mathrm{km}$ ) & $10.77(6.84)$ \\
\hline Bus stop density (unit: $n / h a)$ & $0.59(0.69)$ \\
\hline \multicolumn{2}{|l|}{ Gender (\%) } \\
\hline Male & 50.71 \\
\hline Female & 49.29 \\
\hline \multicolumn{2}{|l|}{ Hukou (\%) } \\
\hline Non-Xiamen hukou & 26.67 \\
\hline Xiamen hukou & 73.33 \\
\hline \multicolumn{2}{|l|}{ Education (\%) } \\
\hline Middle School and below & 47.50 \\
\hline High School to Junior College & 37.91 \\
\hline Undergraduate and above & 14.59 \\
\hline \multicolumn{2}{|l|}{ Occupation (\%) } \\
\hline Blue-collars & 65.51 \\
\hline Students & 11.28 \\
\hline White-collars & 20.10 \\
\hline Officials & 3.11 \\
\hline \multicolumn{2}{|l|}{ Residence type (\%) } \\
\hline Self-owned & 69.10 \\
\hline Danwei-assigned residence & 1.02 \\
\hline Self-rental residence & 29.88 \\
\hline \multicolumn{2}{|l|}{ Family size (\%) } \\
\hline Small family (1 to 2 ) & 30.44 \\
\hline Middle-size family (3 to 7) & 66.35 \\
\hline Large family (8 to 10$)$ & 3.11 \\
\hline \multicolumn{2}{|l|}{ Motor vehicle ownership (\%) } \\
\hline No motor vehicle & 43.25 \\
\hline At least one motor vehicle & 56.75 \\
\hline
\end{tabular}

\subsubsection{Statistical modelling}

The multilevel Tobit regression model and multilevel zero-inflated negative binomial regression model are used in this study. These two kinds of models share a multilevel structure. The utilization of multilevel models is determined by the hierarchical nature of the data. In this study, individuals are nested within 
the communities; certain individuals share the same community built environment, thus probably engendering the spatial dependence issue. Hence, to distinguish between- and within-group differences, address the spatial dependence issue, and avoid the inflated type I error (Hox, 1998), we processed the socio-demographic variables in the first level and the community built environment variables in the second level. It is worth noting that multilevel modeling involves random intercepts and fixed slopes. In both multilevel Tobit model and multilevel zero-inflated negative binomial model, we set a random intercept but fixed slopes. The reasons that we did not set random slopes are mainly for the parsimony of the models because for this study, the hypothesis that Level 1 variables' effects on the dependent variable may vary across Level 2 groups does not have prior-knowledge support, and neither are we interested in the interaction effects between Level 1 and Level 2 independent variables. Further details of the formulas of multilevel modeling can be found in the appendix.

(1) Multilevel Tobit regression model

We use the multilevel Tobit regression model to identify the influencing factors of walking duration. The selection of the Tobit method is decided by the distribution of the dependent variable. Specifically, the walking duration is a continuous variable presenting a skewed distribution with many zero-valued observations, i.e., a left-censored data structure; thus, the fundamental assumption of the ordinary least square (OLS) regression is violated. The Tobit model, as proposed by Tobin (1958), provides a more correct and insightful way of estimating regressions with such skewed-distribution dependent variables (McDonald \& Moffitt, 1980). The Tobit regression model has been frequently used in recent studies (e.g., Lachapelle \& Jean-Germain, 2019; Liu et al., 2017; Ozbilen et al., 2021).

The Tobit model can be expressed by the following formulas (McDonald \& Moffitt, 1980):

$$
y=\left\{\begin{array}{c}
y^{*}=\beta_{0}+\beta_{i} x_{i}+\mu, \mu \mid x_{i} \sim \operatorname{Normal}\left(0, \delta^{2}\right) ; \text { if } y^{*}>0 ; \\
0 ; \text { if } y^{*} \leq 0 .
\end{array}\right.
$$

where the observed dependent variable, $y$, equals the true value of the latent variable $y^{*}$ if $y^{*}$ is greater than 0 and equals 0 if otherwise. The latent variable $y^{*}$ satisfies the assumptions of a typical OLS regression. $\beta_{0}$ denotes the intercept; $\beta_{i}$ denotes the coefficients, which can be interpreted as the coefficients of the OLS regression conditional on the probability that the dependent variable is greater than $0 ; x_{i}$ denotes the independent variables.

(2) Multilevel zero-inflated negative binomial regression model

This model also has a two-level structure with a random intercept and fixed slope, as same as the above Tobit model. Meantime, the selection of zero-inflated negative binomial regression model is out of three aspects of reasons: (a) observed counts $(0,1,2, \ldots, \mathrm{n})$ act as the dependent variable; (b) there are excess zeros in the dependent variable; and (c) over-dispersion exists in the dependent variable (over-dispersion test shows statistical significance with $\mathrm{p}<0.001$ ), thus justifying the use of negative binomial model rather than Poisson model (Yau, Wang, \& Lee, 2003). The formulas are shown as follows:

$$
\begin{aligned}
& \operatorname{Pr}\left(Y_{i}=y\right)=\left\{\begin{array}{c}
\pi+(1-\pi)(1+\kappa \lambda)^{-1 / \kappa}, \text { for } y=0 ; \\
(1-\pi) \frac{\Gamma(y+1 / \kappa)}{\Gamma(y+1) \Gamma(1 / \kappa)} \frac{(\kappa \lambda)^{y}}{(1+\kappa \lambda)^{y+1 / \kappa}}, \text { for } y=1,2,3, \ldots
\end{array}\right. \\
& \lambda=\exp \left(\ln \beta_{0}+\beta_{1} x_{1}+\beta_{2} x_{2}+\cdots+\beta_{n} x_{n}\right)
\end{aligned}
$$


where $Y_{i}$ represents the counts of commuting/non-commuting walking of individual $i$; $\pi$ represents the zero-inflation parameter, namely the probability of being an extra zero; $\kappa$ represents the over-dispersion parameter; $X_{n}$ refers to a vector of independent variables; and $\beta_{n}$ represents the associated coefficients of $x_{n}$.

\section{$4 \quad$ Results}

\subsection{Trip characteristics of commuting and non-commuting walking}

As shown in Table 3, it is obvious that people take more walking trips for non-commuting than for commuting. Specifically, the walkers (i.e., the respondents who took at least one walking trip for commuting or non-commuting purposes during the survey day) took 1.59 walking trips for commuting averagely, while 2.30 trips for non-commuting. The average duration of non-commuting walking (19.33 minutes) is also longer than that of commuting walking (10.17) for walkers.

Table 3. Average frequency and duration of commuting and non-commuting walking

\begin{tabular}{lllllll}
\hline & \multicolumn{3}{c}{ Commuting } & \multicolumn{3}{c}{ Non-commuting } \\
\hline & Sample size & $\begin{array}{l}\text { Frequency } \\
(\text { mean })\end{array}$ & $\begin{array}{l}\text { Duration } \\
(\text { mean })\end{array}$ & Sample size & $\begin{array}{l}\text { Frequency } \\
\text { (mean) }\end{array}$ & $\begin{array}{l}\text { Duration } \\
\text { (mean) }\end{array}$ \\
\hline Entire population & 50,514 & 0.35 & 2.24 & 35,007 & 0.48 & 9.05 \\
Walkers & 11,128 & 1.59 & 10.17 & 16,394 & 2.30 & 19.33 \\
\hline
\end{tabular}

Note: The entire population refers to the respondents who take at least one trip for commuting (or non-commuting). The walkers refer to those who take at least one walking trip.

\subsection{Correlates of commuting and non-commuting walking}

Before building the statistical models, we first run the Pearson's Correlation Test. The results are presented in Table A1 (in the appendix). Obviously, all the built environment variables are relatively weakly correlated, thus avoiding the multicollinearity problem.

Table 4 synthesizes the results of the two multilevel zero-inflated negative binomial regression models and two multilevel Tobit regression models. All the four models are statistically significant.

First of all, almost all the socio-demographic variables are significantly associated with both kinds of walking. Interestingly, some variables are associated with such two kinds of walking in the opposite directions, including age, occupation, family size, and residence type. Specifically, age is negatively associated with the frequency and duration of commuting walking and yet positively correlated with noncommuting walking, indicating that residents' tendency of non-commuting walking increases with age, while their commuting walking decreases with it. Compared with blue-collars, students, white-collars and officials have a higher frequency and longer duration for commuting walking but a lower frequency and shorter duration for non-commuting walking. People living in danwei-assigned residences or selfrental residences tend to walk more frequently and longer for commuting compared with those living in self-owned residences, yet the frequency and duration of their non-commuting walking are smaller and shorter. Besides, females significantly walk more frequently and longer than males, no matter for commuting or non-commuting. Educational attainment is negatively associated with commuting and non-commuting walking, meaning the more educated people tend to walk less. In addition, as expected, motor vehicle availability significantly decreases the tendency of walking. 
In terms of built environment variables, things get more complicated. Community population density, which is found to be a significant facilitator for walking in prior studies, is only significantly positively associated with the frequency and duration of walking for non-commuting purpose, and only in the lower and middle range. More specifically, below 600 people per hectare, population density can significantly promote frequency and duration of non-commuting walking, while above 600 people per hectare, it is not significantly associated with walking any more. Land-use mix is significantly positively correlated with the frequency and duration of walking for both commuting and non-commuting purposes. Distance to the city center is significantly negatively associated with both two kinds of walking, meaning that those living closer to the central city tend to walk more. Daily public facility density is shown to significantly increase both frequency and duration of walking for non-commuting, whereas it has no significant effects on commuting walking. In addition, job density, bus stop density, and intersection density are not significantly associated with any walking.

To test the reliability of the results, we randomly extract $30 \%$ of the samples to re-build the models. Table A2 in the appendix presents the results based on the subsets. As shown, results in Tables A2 and 4 are highly consistent with each other, thus validating the reliability of our models.

Moreover, to examine whether the correlates of walking for commuting are significantly different from those for non-commuting, we conduct significance tests to compare the coefficients of the same variables. Specifically, we combine the samples of walking for commuting and non-commuting, add a dummy variable indicating the walking purposes and interaction terms between the dummy variable and all socio-demographic and built-environment variables, and re-build the models. Table A3 in the appendix presents the results. It is found that the majority of the interaction terms between the walking purpose dummy (commuting or non-commuting) and socio-demographic and built-environment variables are statistically significant, which indicates that the majority of the independent variables have significantly different relationships with walking for commuting and non-commuting.

Table 4. Results of multilevel zero-inflated negative binomial regression and multilevel Tobit regression

\begin{tabular}{|c|c|c|c|c|}
\hline \multirow[t]{2}{*}{ Variables } & \multicolumn{2}{|c|}{ Frequency } & \multicolumn{2}{|c|}{ Duration } \\
\hline & $\begin{array}{l}\text { Commuting } \\
\text { Coef. }[z]\end{array}$ & $\begin{array}{l}\text { Non-commuting } \\
\text { Coef. }[z]\end{array}$ & $\begin{array}{l}\text { Commuting } \\
\text { Coef. }[z]\end{array}$ & $\begin{array}{l}\text { Non-commuting } \\
\text { Coef. }[z]\end{array}$ \\
\hline \multicolumn{5}{|l|}{ Level 1 variables } \\
\hline Age & $-0.02^{* *}[-2.03]$ & $0.01^{* * *}[19.09]$ & $-0.03[-0.60]$ & $0.82^{* * *}[30.30]$ \\
\hline \multicolumn{5}{|l|}{ Gender } \\
\hline Male & Ref. & Ref. & Ref. & Ref. \\
\hline Female & $0.35^{* * *}[18.64]$ & $0.28^{* * *}[21.40]$ & $15.86^{* * *}[19.69]$ & $17.72^{* * *}[25.40]$ \\
\hline \multicolumn{5}{|l|}{ Hukou } \\
\hline Non-Xiamen hukou & Ref. & Ref. & Ref. & Ref. \\
\hline Xiamen hukou & $0.02[0.56]$ & $-0.05^{* *}[-2.43]$ & $-1.18[-0.85]$ & $-6.20^{* * *}[-5.67]$ \\
\hline \multicolumn{5}{|l|}{ Education } \\
\hline Middle School and below & Ref. & Ref. & Ref. & Ref. \\
\hline High School to Junior College & $-0.54^{* * *}[-19.65]$ & $-0.08^{* * *}[-5.50]$ & $-22.67^{* * *}[-22.31]$ & $-6.50^{* * *}[-8.28]$ \\
\hline Undergraduate and above & $-0.94^{* * *}[-22.9]$ & $-0.16^{* * *}[-5.85]$ & $-32.72^{* * *}[-22.04]$ & $-8.16^{* * *}[-5.92]$ \\
\hline \multicolumn{5}{|l|}{ Occupation } \\
\hline Blue-collars & Ref. & Ref. & Ref. & Ref. \\
\hline Students & $0.94^{* * *}[23.25]$ & $-0.13^{* *}[-2.74]$ & $38.12^{* * *}[22.64]$ & $-12.54^{* * *}[-5.71]$ \\
\hline White-collars & $0.06^{* *}[1.96]$ & $-0.32^{* * *}[-11.99]$ & $2.03^{*}[1.87]$ & $-8.11^{* * *}[-6.34]$ \\
\hline
\end{tabular}




\begin{tabular}{|c|c|c|c|c|}
\hline \multirow[t]{2}{*}{ Variables } & \multicolumn{2}{|c|}{ Frequency } & \multicolumn{2}{|c|}{ Duration } \\
\hline & $\begin{array}{l}\text { Commuting } \\
\text { Coef. }[z]\end{array}$ & $\begin{array}{l}\text { Non-commuting } \\
\text { Coef. }[z]\end{array}$ & $\begin{array}{l}\text { Commuting } \\
\text { Coef. }[z]\end{array}$ & $\begin{array}{l}\text { Non-commuting } \\
\text { Coef. }[z]\end{array}$ \\
\hline Officials & $0.23^{* *}[3.12]$ & $-0.39^{* * *}[-6.53]$ & $6.15^{* * *}[2.48]$ & $-13.46^{* * *}[-5.02]$ \\
\hline \multicolumn{5}{|l|}{ Family size } \\
\hline Small family (1 to 2 ) & Ref. & Ref. & Ref. & Ref. \\
\hline Middle-size family (3 to 7) & $-0.12^{* * *}[-5.27]$ & $0.10^{* * *}[7.69]$ & $-5.87^{* * *}[-5.97]$ & $2.57^{* * *}[3.36]$ \\
\hline Large family (8 to 10$)$ & $-0.18^{* *}[-2.62]$ & $0.16^{* * *}[4.43]$ & $-8.65^{* * *}[-3.20]$ & $4.17^{* *}[2.06]$ \\
\hline Residence size $\left(\mathbf{m}^{2}\right)$ & $-0.01^{*}[-1.89]$ & $-0.01^{* * *}[-3.35]$ & $-0.03^{* *}[-3.11]$ & $-0.04^{* * *}[-5.18]$ \\
\hline \multicolumn{5}{|l|}{ Residence type } \\
\hline Self-owned & Ref. & Ref. & Ref. & Ref. \\
\hline Danwei-assigned residence & $0.13[1.62]$ & $-0.05[-0.86]$ & $6.65^{*}[1.73]$ & $-3.03[-0.95]$ \\
\hline Self-rental residence & $0.10^{* *}[3.00]$ & $-0.05^{* *}[-2.36]$ & $4.98^{* * *}[3.57]$ & $-3.08^{* *}[-2.75]$ \\
\hline \multicolumn{5}{|l|}{ Motor vehicle ownership } \\
\hline No vehicle & Ref. & Ref. & Ref. & Ref. \\
\hline At least one vehicle & $-0.28^{* * *}[-12.54]$ & $-0.10^{* * *}[-7.13]$ & $-14.73^{* * *}[-15.23]$ & $-10.06^{* * *}[-12.70]$ \\
\hline \multicolumn{5}{|l|}{ Level 2 variables } \\
\hline \multicolumn{5}{|l|}{ Population density } \\
\hline $0-100$ per ha & Ref. & Ref. & Ref. & Ref. \\
\hline $100-300$ per ha & $0.17[1.61]$ & $0.21^{* *}[2.38]$ & $5.08[1.46]$ & $8.89^{* *}[2.60]$ \\
\hline $300-600$ per ha & $0.18[1.54]$ & $0.24^{* *}[2.42]$ & $6.55[1.36]$ & $9.55^{* *}[2.44]$ \\
\hline $600-900$ per ha & $0.12[0.87]$ & $0.15[1.20]$ & $3.81[0.79]$ & $3.09[0.64]$ \\
\hline Job density & $0.01[-0.30]$ & $0.00[0.17]$ & $-0.05[-0.17]$ & $-0.15[-0.56]$ \\
\hline Land-use mix (Entropy) & $0.88^{* * *}[5.10]$ & $0.68^{* * *}[4.87]$ & $28.05^{* * *}[4.72]$ & $20.98^{* * *}[3.74]$ \\
\hline Intersection density & $-0.03[-0.18]$ & $0.07[0.58]$ & $0.76[0.15]$ & $6.30[1.25]$ \\
\hline Distance to city center & $-0.02^{* * *}[-3.74]$ & $-0.01^{* *}[-3.05]$ & $-0.66^{* * *}[-4.29]$ & $-0.59^{* * *}[-3.92]$ \\
\hline Bus stop density & $0.02[0.34]$ & $0.03[0.57]$ & $0.32[0.16]$ & $3.17[0.63]$ \\
\hline Daily public facility density & $0.02[1.41]$ & $0.02^{* *}[2.06]$ & $0.43[1.02]$ & $0.75^{* *}[1.98]$ \\
\hline Sample size & 50,514 & 35,007 & 50,514 & 35,007 \\
\hline ICC & 0.164 & 0.190 & 0.170 & 0.195 \\
\hline Over-dispersion parameter $(\kappa)$ & 1.973 & 1.001 & N/A & \\
\hline Zero-inflation $(\pi)$ & 0.450 & 0.344 & N/A & \\
\hline Log-likelihood & -42099.6 & -45803.1 & -75512.3 & -99018.376 \\
\hline AIC & 84257.2 & 91664.2 & 151080.6 & 198092.8 \\
\hline
\end{tabular}

Note: Coef. $=$ Coefficient; $[\mathrm{z}]=\mathrm{z}$ value; Ref. $=$ Reference; ${ }^{*} \mathrm{p}<0.1 ;{ }^{* *} \mathrm{p}<0.05 ;{ }^{* *} \mathrm{p}<0.001$.

\section{Discussion}

In this analysis, we comparatively examine the characteristics and correlates of transportation walking for commuting and non-commuting purposes. We have the following findings.

Our first finding is that non-commuting walking on average has a higher frequency and longer duration than commuting walking, implying the disadvantage of walking as a commuting mode owing to its relatively low speed and efficiency. This finding is in line with some prior studies, as Chan et al. (2019) revealed that people tend to make more walking trips for household responsibilities than for workplace/school, and Zhao and Wan (2020) found that living walking has a longer duration than 
commuting walking.

Moreover, we find that most socio-demographic variables are significant indicators of both types of walking. Interestingly, age, occupation, family size, and residence type are correlated with commuting and non-commuting walking in the opposite directions, indicating that those variables that increase walking for one purpose decrease walking for the other purpose at the same time. This, to a certain extent, provides some convincing evidence for the existence of a "transportation walking budget," which is comparable to the "physical activity budget" (Forsyth et al., 2008; Forsyth et al., 2009). Under the constraints of energy, time, enthusiasm, etc., people who walk for commuting more may walk for noncommuting less, and vice versa. When proposing interventions for promoting walking, decision makers should consider this phenomenon and be cautious about the complex effects on different types of walking. Females walk more frequently and longer than males, especially for non-commuting purpose; older people significantly walk less for commuting. These gender and age differences in walking behavior are highly consistent with findings of some prior studies (e.g., Ghani et al., 2016; Neves et al., 2021). This finding is also understandable. More often than not, females are burdened with more family responsibilities in China. Older people's lower walking frequency can be attributed to their life stage; as they age, they may have better access to transportation resources, undertake more important responsibilities, or be retired. In addition, residence size and motor vehicle ownership, as indicators of household income, transportation resource, and socio-economic status, are both significantly negatively associated with walking frequency and duration, which coincides with our expectation and the existing evidence (Hatamzadeh et al., 2020; Neves et al., 2021; Zhao \& Wan, 2020) The ascertained significant effects of socio-demographic variables reveal the differentiations of walking behaviors across diverse population subgroups and remind that policy-makers should endeavor to figure out targeted intervention measures to promote walking of different groups.

More importantly, this study reveals the complicated effects of built environment variables on walking.

First, on the whole, the built environment has much more pronounced effects on non-commuting walking than on commuting walking. This finding is in accord with that of Zhao and Wan (2020), which found that commuting walking was less associated with neighborhood built environment. This phenomenon is determined by the nature and features of these two types of walking. Understandably, commuting walking is more constrained spatially and temporally, whereas non-commuting walking can be much more flexible (Ding et al., 2017). Hence, the degree of freedom of non-commuting walking decides its high responsiveness to the built environment. In addition, unlike non-commuting walking trips, a higher proportion of commuting walking trips may be beyond the community range (Cho \& Rodríguez, 2015), thus possibly weakening the effects of community built environment on commuting walking.

Second, despite its significant positive effects on non-commuting walking, population density has no effects on commuting walking whatsoever. This finding diverges from the findings of many studies in the developed context (e.g., Christiansen et al., 2016; Kamruzzaman et al., 2016; Wang et al., 2021); these studies confirmed the significant effects of population (or residential) density on transportation walking. Unlike Western cities, where the city center has much higher density while the outer areas are characterized with low-density sprawling, many cities in China have undergone a high-density expansion (Calthorpe, 2016); a community with a higher population density is not necessarily closer to the city center, where jobs gather, and thus living in such a community does not necessarily lead to shorter commuting distance. By contrast, non-commuting walking can benefit from higher population density because the latter oftentimes results in the concentration of public facilities. However, it is noteworthy that population density is only significantly associated with non-commuting walking in its small-tomiddle range, indicating a potential threshold effect, echoing the finding of Lu et al. (2017). The under- 
lying reason may be that excessively high population/residential density probably make the environment less desirable for non-commuting walking by bringing about crowdedness and traffic congestion (Zhao \& Wan, 2020).

Third, land-use mix is significantly correlated with the frequency and duration of both commuting and non-commuting walking, echoing the findings of a plethora of prior studies in both developed and developing contexts (e.g., Christiansen et al., 2016; Kang et al., 2017; Neves et al., 2021; Vale \& Pereira, 2016; Wang et al., 2021). More mixed-use development patterns put different urban functions (commercial, public services, educational, employment, and residential) closer to each other, thus shortening the distance to commuting and non-commuting destinations and making walking more convenient (Cheng et al., 2020). In addition, a longer distance to the city center is found to significantly decrease both types of walking, which is also congruent with many existing studies (e.g., Chudyk et al., 2015; Næss et al., 2019). As the city center gathers a large proportion of commuting and non-commuting destinations, living in communities closer to the city center can lead to a shorter trip distance, thus attracting more walking behaviors (Liu et al., 2021). Daily public facility density, as expected, is only significantly associated with non-commuting walking. In small-to-medium-sized cities, accessibility of such daily public facilities as vegetable markets, breakfast stores, and cultural palaces are rather important to people's daily routine life. The significant effects of daily public facilities on walking are also confirmed in some similar medium-sized cities in China, such as Nanjing (Cheng, Caset, et al., 2019), Nanning (Shen et al., 2020), and Zhongshan (Zhang et al., 2014).

Fourth, unexpectedly, job density, intersection density, and bus stop density are all insignificant correlates. Community job density was found to significantly promote walking, especially walking to workplace (Huang et al., 2019); however, in the context of Chinese cities, high job density does not necessarily lead to good job-housing balance. As Ta et al. (2017) found, in China, especially in some monocentric cities, apart from the common "inward commuting" (i.e., from suburban to city center), "lateral commuting" (commuting between suburban areas) and "reverse commuting" (from the city center to suburban) are also prevalent. The latter two types of commuting imply that people who reside in high-job-density areas may still have long commuting distances (Ta et al., 2017). Higher intersection density was widely found to significantly increase walking, especially in the developed context (Kang et al., 2017; Koohsari et al., 2017) because higher intersection density, namely better-connected streets, can provide more direct paths for pedestrians and shorten the trip distance (Koohsari et al., 2014). However, in Chinese cities, even in many medium-sized cities (Sun et al., 2017), as the motorization level increases rapidly (Wang \& Yuan, 2013), motor vehicles have dominated the roads, thus making the intersections increasingly less safe to cross. The dominance of automobiles and the aggravated traffic conditions have probably counteracted the potential conducive effects of high intersection density on walking. Also, this finding coincides with a study in Beijing (Zhao \& Wan, 2020). In contrast to some prior studies (e.g., Kang, 2018; Wang \& Cao, 2017), which confirmed the significant effects of bus stop density on walking, in the context of Xiamen, bus stop density has no significant relationships with both types of walking. Better access to public transport can attract pedestrians to/from bus stops and thus bring a good walking atmosphere; areas with better public transit accessibility can also lead to the gathering of public facilities, thus providing various destinations for walking (Cheng et al., 2020; Hou, 2019). However, public transport has a substitution effect for non-motorized modes like walking (Cats et al., 2014), thus probably offsetting the beneficial effects of higher bus stop density on walking.

In sum, this study reveals the substantial differences in the characteristics and socio-demographic and built environment correlates of walking for commuting and non-commuting. It enlightens policymakers and practitioners about the importance of distinguishing between different types of walking; moreover, it informs them that efforts aimed at promoting walking should provide targeted and tailored interventions and avoid "one-size-fits-all" policies. The findings of this study also highlight the differ- 
ences between China and the developed context; hence, prudence is required when attempting to apply research findings obtained in the West. Meanwhile, similarities and differences exist between the findings of this study and studies focusing on some star cities in China, such as Beijing (Zhao \& Wan, 2020) and Shenzhen (Chan et al., 2019). This phenomenon implies the potential uniqueness of medium-sized cities like Xiamen in walking behavior. Moreover, given the scarcity of academic attention toward those less dazzling cities, further explorations are recommended.

\section{Conclusion}

This study, taking Xiamen as a case study, looks into walking for transportation and its influencing factors comparatively, distinguishing between commuting and non-commuting purposes. It finds that non-commuting walking is averagely more frequent and longer than commuting walking. More importantly, the effects of socio-demographic and built environment characteristics on walking are quite different between commuting and non-commuting purposes, especially those of built environment.

To the best of our knowledge, this study is among the earliest efforts focusing on commuting and non-commuting transportation walking in China's context. It can help the policy-makers and practitioners understand the differentiations between different domains of walking and provide targeted interventions for promoting walking accordingly.

Without any doubts, this study also has some limitations. First, as a cross-sectional analysis, this study can only derive correlation. In future works, longitudinal data and/or quasi-natural experimental research design can be adopted to fathom causality. Second, the travel data this study employed was self-reported, thus possibly generating errors and inaccuracies. Third, due to the limitation of data source, psychological and/or attitudinal factors were not included; hence the self-selection effect was not considered. Moreover, future works can try to compare built environment variables across different geographical scales (e.g., community level vs. district level) to see if their effects on walking (in particular, commuting walking) differ. 


\section{References}

Bentley, R., Blakely, T., Kavanagh, A., Aitken, Z., King, T., McElwee, P., . . Turrell, G. (2018). A longitudinal study examining changes in street connectivity, land use, and density of dwellings and walking for transport in Brisbane, Australia. Environmental Health Perspectives, 126(5), 057003.

Boakye-Dankwa, E., Barnett, A., Pachana, N. A., Turrell, G., \& Cerin, E. (2019). Associations between latent classes of perceived neighborhood destination accessibility and walking behaviors in older adults of a low-density and a high-density city. Journal of Aging and Physical Activity, 27(4), 553-564.

Boakye-Dankwa, E., Nathan, A., Barnett, A., Busija, L., Lee, R. S., Pachana, N., . . Cerin, E. (2019). Walking behaviour and patterns of perceived access to neighborhood destinations in older adults from a low-density (Brisbane, Australia) and an ultra-dense city (Hong Kong, China). Cities, 84, 23-33.

Calthorpe, P. (2016). China chokes on high-density sprawl. Retrieved from https://www.cnu.org/publicsquare/china-chokes-high-density-sprawl

Cats, O., Reimal, T., \& Susilo, Y. (2014). Public transport pricing policy: Empirical evidence from a fare-free scheme in Tallinn, Estonia. Transportation Research Record, 2415(1), 89-96.

Celis-Morales, C. A., Lyall, D. M., Welsh, P., Anderson, J., Steell, L., Guo, Y., . . Sattar, N. (2017). Association between active commuting and incident cardiovascular disease, cancer, and mortality: Prospective cohort study. The BMJ, 357, j1456.

Chan, E. T., Schwanen, T., \& Banister, D. (2019). The role of perceived environment, neighbourhood characteristics, and attitudes in walking behaviour: Evidence from a rapidly developing city in China. Transportation, 48, 431-454.

Cheng, L., Caset, F., De Vos, J., Derudder, B., \& Witlox, F. (2019). Investigating walking accessibility to recreational amenities for elderly people in Nanjing, China. Transportation Research Part D: Transport and Environment, 76, 85-99.

Cheng, L., Chen, X., Yang, S., Cao, Z., De Vos, J., \& Witlox, F. (2019). Active travel for active aging in China: The role of built environment. Journal of Transport Geography, 76, 142-152.

Cheng, L., De Vos, J., Zhao, P., Yang, M., \& Witlox, F. (2020). Examining non-linear built environment effects on elderly's walking: A random forest approach. Transportation Research Part D: Transport and Environment, 88, 102552.

Cho, G.-H., \& Rodríguez, D. A. (2015). Neighborhood design, neighborhood location, and three types of walking: Results from the Washington, DC area. Environment and Planning B: Planning and Design, 42(3), 526-540.

Christiansen, L. B., Cerin, E., Badland, H., Kerr, J., Davey, R., Troelsen, J., . . Sugiyama, T. (2016). International comparisons of the associations between objective measures of the built environment and transport-related walking and cycling: IPEN adult study. Journal of Transport \& Health, 3(4), 467-478.

Chudyk, A. M., Winters, M., Moniruzzaman, M., Ashe, M. C., Gould, J. S., \& McKay, H. (2015). Destinations matter: The association between where older adults live and their travel behavior. Journal of Transport \& Health, 2(1), 50-57.

Day, K. (2016). Built environmental correlates of physical activity in China: A review. Preventive Medicine Reports, 3, 303-316.

Ding, C., Liu, C., Zhang, Y., Yang, J., \& Wang, Y. (2017). Investigating the impacts of built environment on vehicle miles traveled and energy consumption: Differences between commuting and noncommuting trips. Cities, 68, 25-36.

Ding, C., Wang, Y., Tang, T., Mishra, S., \& Liu, C. (2018). Joint analysis of the spatial impacts of built environment on car ownership and travel mode choice. Transportation Research Part D: Transport and 
Environment, 60, 28-40.

Ewing, R., \& Cervero, R. (2001). Travel and the built environment: A synthesis. Transportation Research Record, 1780(1), 87-114.

Ewing, R., \& Cervero, R. (2010). Travel and the built environment: A meta-analysis. Journal of the American Planning Association, 76(3), 265-294.

Ewing, R., Greenwald, M., Zhang, M., Walters, J., Feldman, M., Cervero, R., \& Thomas, J. (2009). Measuring the impact of urban form and transit access on mixed use site trip generation rates-Portland pilot study. Washington, DC: US Environmental Protection Agency.

Ewing, R., Tian, G., Goates, J., Zhang, M., Greenwald, M. J., Joyce, A., . . Greene, W. (2015). Varying influences of the built environment on household travel in 15 diverse regions of the United States. Urban Studies, 52(13), 2330-2348.

Fan, J. X., Wen, M., \& Wan, N. (2017). Built environment and active commuting: Rural-urban differences in the US. SSM-Population Health, 3, 435-441.

Forsyth, A., Hearst, M., Oakes, J. M., \& Schmitz, K. H. (2008). Design and destinations: Factors influencing walking and total physical activity. Urban Studies, 45(9), 1973-1996.

Forsyth, A., Oakes, J. M., Lee, B., \& Schmitz, K. H. (2009). The built environment, walking, and physical activity: Is the environment more important to some people than others? Transportation Research Part D: Transport and Environment, 14(1), 42-49.

Ghani, F., Rachele, J. N., Washington, S., \& Turrell, G. (2016). Gender and age differences in walking for transport and recreation: Are the relationships the same in all neighborhoods? Preventive Medicine Reports, 4, 75-80.

Giles-Corti, B., Timperio, A., Bull, F., \& Pikora, T. (2005). Understanding physical activity environmental correlates: Increased specificity for ecological models. Exercise and Sport Sciences Reviews, 33(4), 175-181.

Handy, S., Cao, X., \& Mokhtarian, P. L. (2006). Self-selection in the relationship between the built environment and walking: Empirical evidence from Northern California. Journal of the American Planning Association, 72(1), 55-74.

Hanson, S., \& Jones, A. (2015). Is there evidence that walking groups have health benefits? A systematic review and meta-analysis. British Journal of Sports Medicine, 49(11), 710-715.

Hatamzadeh, Y., Habibian, M., \& Khodaii, A. (2020). Measuring walking behavior in commuting to work: Investigating the role of subjective, environmental and socioeconomic factors in a structural model. International Journal of Urban Sciences, 24(2), 173-188.

Herrmann-Lunecke, M. G., Mora, R., \& Vejares, P. (2021). Perception of the built environment and walking in pericentral neighbourhoods in Santiago, Chile. Travel Behavior and Society, 23, 192-206.

Hou, Y. (2019). Polycentric urban form and non-work travel in Singapore: A focus on seniors. Transportation Research Part D: Transport and Environment, 73, 245-275.

Hox, J. (1998). Multilevel modeling: When and why. In Classification, data analysis, and data highways (pp. 147-154). New York: Springer.

Huang, R., Moudon, A. V., Zhou, C., \& Saelens, B. E. (2019). Higher residential and employment densities are associated with more objectively measured walking in the home neighborhood. Journal of Transport \& Health, 12, 142-151.

Kamruzzaman, M., Washington, S., Baker, D., Brown, W., Giles-Corti, B., \& Turrell, G. (2016). Built environment impacts on walking for transport in Brisbane, Australia. Transportation, 43(1), 53-77.

Kang, B., Moudon, A. V., Hurvitz, P. M., \& Saelens, B. E. (2017). Differences in behavior, time, location, and built environment between objectively measured utilitarian and recreational walking. Transportation Research Part D: Transport and Environment, 57, 185-194.

Kang, C.-D. (2017). Measuring the effects of street network configurations on walking in Seoul, Korea. Cities, 71, 30-40. 
Kang, C.-D. (2018). The $S+5$ Ds: Spatial access to pedestrian environments and walking in Seoul, Korea. Cities, 77, 130-141.

Koohsari, M. J., Sugiyama, T., Lamb, K. E., Villanueva, K., \& Owen, N. (2014). Street connectivity and walking for transport: Role of neighborhood destinations. Preventive Medicine, 66, 118-122.

Koohsari, M. J., Sugiyama, T., Shibata, A., Ishii, K., Liao, Y., Hanibuchi, T., . . Oka, K. (2017). Associations of street layout with walking and sedentary behaviors in an urban and a rural area of Japan. Health \& Place, 45, 64-69.

Lachapelle, U., \& Jean-Germain, F. (2019). Personal use of the Internet and travel: Evidence from the Canadian General Social Survey's 2010 time use module. Travel Behavior and Society, 14, 81-91.

Larrañaga, A. M., Rizzi, L. I., Arellana, J., Strambi, O., \& Cybis, H. B. B. (2016). The influence of built environment and travel attitudes on walking: A case study of Porto Alegre, Brazil. International Journal of Sustainable Transportation, 10(4), 332-342.

Lee, I.-M., \& Buchner, D. M. (2008). The importance of walking to public health. Medicine \& Science in Sports \& Exercise, 40(7), S512-S518.

Lin, L., \& Moudon, A. V. (2010). Objective versus subjective measures of the built environment, which are most effective in capturing associations with walking? Health \& Place, 16(2), 339-348.

Litman, T. (2010). Quantifying the benefits of nonmotorized transportation for achieving mobility management objectives. Victoria, BC, Canada: Victoria Transport Policy Institute.

Liu, C., Susilo, Y. O., \& Karlström, A. (2017). Jointly modelling individual's daily activity-travel time use and mode share by a nested multivariate Tobit model system. Transportmetrica A: Transport Science, 13(6), 491-518.

Liu, J., Wang, B., \& Xiao, L. (2021). Non-linear associations between built environment and active travel for working and shopping: An extreme gradient boosting approach. Journal of Transport Geography, 92, 103034.

Lu, Y., Sun, G., Sarkar, C., Gou, Z., \& Xiao, Y. (2018). Commuting mode choice in a high-density city: Do land-use density and diversity matter in Hong Kong? International Journal of Environmental Research and Public Health, 15(5), 920.

Lu, Y., Xiao, Y., \& Ye, Y. (2017). Urban density, diversity and design: Is more always better for walking? A study from Hong Kong. Preventive Medicine, 103, S99-S103.

Maizlish, N., Linesch, N. J., \& Woodcock, J. (2017). Health and greenhouse gas mitigation benefits of ambitious expansion of cycling, walking, and transit in California. Journal of Transport \& Health, 6 , 490-500.

McDonald, J. F., \& Moffitt, R. A. (1980). The uses of Tobit analysis. The Review of Economics and Statistics, 62(2)318-321.

McKenzie, B. (2017). Modes less traveled_bicycling and walking to work in the United States: 20082012. Washington, DC: U.S. Census Bureau.

Næss, P., Strand, A., Wolday, F., \& Stefansdottir, H. (2019). Residential location, commuting and non-work travel in two urban areas of different size and with different center structures. Progress in Planning, 128, 1-36.

Neves, C. E. T., da Silva, A. R., \& de Arruda, F. S. (2021). Exploring the link between built environment and walking choice in São Paulo city, Brazil. Journal of Transport Geography, 93, 103064.

Ng, S. W., Norton, E. C., \& Popkin, B. M. (2009). Why have physical activity levels declined among Chinese adults? Findings from the 1991-2006 China Health and Nutrition Surveys. Social Science \& Medicine, 68(7), 1305-1314.

Ozbilen, B., Wang, K., \& Akar, G. (2021). Revisiting the impacts of virtual mobility on travel behavior: An exploration of daily travel time expenditures. Transportation Research Part A: Policy and Practice, 145, 49-62. 
Paul, P., Carlson, S. A., Carroll, D. D., Berrigan, D., \& Fulton, J. E. (2015). Walking for transportation and leisure among US adults-National Health Interview Survey 2010. Journal of Physical Activity and Health, 12(s1), S62-S69.

Pucher, J., Buehler, R., Bassett, D. R., \& Dannenberg, A. L. (2010). Walking and cycling to health: A comparative analysis of city, state, and international data. American Journal of Public Health, 100(10), 1986-1992.

Saelens, B. E., \& Handy, S. L. (2008). Built environment correlates of walking: A review. Medicine and Science in Sports and Exercise, 40 (7 Suppl), S550.

Schneider, R. J. (2015). Local environment characteristics associated with walking and taking transit to shopping districts. Journal of Transport and Land Use, 8(2), 125-147.

Shen, J., Cheng, J., Huang, W., \& Zeng, F. (2020). An exploration of spatial and social inequalities of urban sports facilities in Nanning City, China. Sustainability, 12(11), 4353.

Sun, B., Zhang, T., He, Z., \& Wang, R. (2017). Urban spatial structure and motorization in China. Journal of Regional Science, 57(3), 470-486.

Ta, N., Chai, Y., Zhang, Y., \& Sun, D. (2017). Understanding job-housing relationship and commuting pattern in Chinese cities: Past, present and future. Transportation Research Part D: Transport and Environment, 52, 562-573.

Tobin, J. (1958). Estimation of relationships for limited dependent variables. Econometrica: Journal of the Econometric Society, 24-36.

Tschentscher, M., Niederseer, D., \& Niebauer, J. (2013). Health benefits of Nordic walking: A systematic review. American Journal of Preventive Medicine, 44(1), 76-84.

Vale, D. S., \& Pereira, M. (2016). Influence on pedestrian commuting behavior of the built environment surrounding destinations: A structural equations modeling approach. International Journal of Sustainable Transportation, 10(8), 730-741.

Wang, J., \& Cao, X. (2017). Exploring built environment correlates of walking distance of transit egress in the Twin Cities. Journal of Transport Geography, 64, 132-138.

Wang, R., \& Yuan, Q. (2013). Parking practices and policies under rapid motorization: The case of China. Transport Policy, 30, 109-116.

Wang, Z., Ettema, D., \& Helbich, M. (2021). Objective environmental exposures correlate differently with recreational and transportation walking: A cross-sectional national study in the Netherlands. Environmental Research, 194, 110591.

Wood, L., Frank, L. D., \& Giles-Corti, B. (2010). Sense of community and its relationship with walking and neighborhood design. Social Science \& Medicine, 70(9), 1381-1390.

Yang, L., Wang, Y., Han, S., \& Liu, Y. (2019). Urban transport carbon dioxide (CO2) emissions by commuters in rapidly developing cities: The comparative study of Beijing and Xi'an in China. Transportation Research Part D: Transport and Environment, 68, 65-83.

Yau, K. K., Wang, K., \& Lee, A. H. (2003). Zero-inflated negative binomial mixed regression modeling of over-dispersed count data with extra zeros. Biometrical Journal: Journal of Mathematical Methods in Biosciences, 45, 437-452.

Zhang, Y., Li, Y., Liu, Q., \& Li, C. (2014). The built environment and walking activity of the elderly: An empirical analysis in the Zhongshan metropolitan area, China. Sustainability, 6(2), 1076-1092.

Zhao, P., \& Wan, J. (2020). Examining the effects of neighborhood design on walking in growing megacity. Transportation Research Part D: Transport and Environment, 86, 102417.

\section{Appendix}

Appendix available at https://www.jtlu.org/index.php/jtlu/article/view/1933 